\title{
Geographical Patterns in Drug-Related Mortality and Suicide: Investigating Commonalities in English Small Areas
}

\section{Peter Congdon}

School of Geography, Queen Mary University of London, Mile End Rd, London E1 4NS, UK; p.congdon@qmul.ac.uk

Received: 24 April 2019; Accepted: 21 May 2019; Published: 23 May 2019

\begin{abstract}
There are increasing concerns regarding upward trends in drug-related deaths in a number of developed societies. In some countries, these have been paralleled by upward trends in suicide. Of frequent concern to public health policy are local variations in these outcomes, and the factors underlying them. In this paper, we consider the geographic pattern of drug-related deaths and suicide for 2012-2016 across 6791 small areas in England. The aim is to establish the extent of commonalities in area risk factors between the two outcomes, with a particular focus on impacts of deprivation, fragmentation and rurality.
\end{abstract}

Keywords: drug-related deaths; suicides; small areas; deprivation; social fragmentation; rurality

\section{Introduction}

There are increasing concerns regarding upward trends in drug-related deaths in certain developed societies, including the US [1,2] and the countries constituting the UK, such as England and Scotland [3]. Almost a third of drug-related deaths in 2015 in Europe happened in the UK. Trends in suicide in countries experiencing growth in drug-related deaths are less consistent: suicide in the US has increased in the last decade [4], while in the UK there is a more stable pattern in suicide rates in recent years.

There are aetiological similarities between suicide and drug-related death, as harmful drug misuse may be considered a form of self-injurious behaviour [5]. Indeed, Case and Deaton [6] combine suicide, drug and alcohol misuse mortality, and cirrhosis as "deaths of despair". For example, Al-Sharqi et al. [7] discuss commonalities in risk factors for self-injurious behaviour and substance abuse, "including coexisting mental and physical disorders, impulsivity, problem drinking, partner relationship problems, significant life stressors and events, previous suicide attempts, and lack of social and family support".

There are also overlaps between these events from a point of view of diagnostic classification, such that Rockett et al. [8] proposed a combined category of self-injury mortality, including suicides and deaths from opioid and other drug self-intoxication. This reflects the fact that many suicides may be hidden among accidental drug-related deaths $[9,10]$.

Of frequent concern to public health policy are local variations in these outcomes, and the factors underlying them. Much focus has been on individual risk factors for drug misuse and self-harming behaviour, but a full perspective involves consideration of community influences [11,12]. In the case of mortality, individual event data and individual risk factor profiles are usually not available, and analysis of spatial contrasts is therefore important. Spatial variations will in part reflect variations in the composition of populations, and ultimately the operation of risk factors at individual level (compositional influences). However, they may also reflect distinct place effects (contextual influences) [13,14]. 
The literature on spatial patterns in drug-related mortality, and the ecological (area level) influences) on such mortality, has focused especially on the influence of area socio-economic status $[15,16]$, urban status [17], and area social cohesion [18]. Most published papers at small area level concern the US, though Griffiths et al. [8] considered drug-related deaths in England and Wales according to an urban settlement classification of electoral wards. Small area studies of suicide are more plentiful, including applications to UK, US and Australia $[4,19,20]$.

In this paper, we consider the geographic pattern of drug-related deaths and of suicide, for the five year period 2012-2016. The data consist of all registered deaths from these causes across England, with 15,123 drug-related deaths ( $67.8 \%$ of the total is for males; $32.2 \%$ for females), and 23,517 suicides ( $76.3 \%$ of the total is for males, and $23.7 \%$ for females). They are based on usual residence at time of death, and may have been referred to a Coroner before registration; see Section 6.1 in [21]. The International Classification of Diseases (ICD) ranges for these data used are consistent with official definitions of drug-related deaths and of suicides, as in official reports by the UK Office for National Statistics [22,23]. The ICD ranges are specified in Appendix A, which includes a discussion of a definitional overlap between the two events due to drug-related suicides. This overlap is more relevant to females, since "violent and highly lethal methods such as firearm suicide and hanging are more frequent among men, whereas women often choose poisoning or drowning, which are less violent and less lethal." [24]

The data were requested from the UK Office for National Statistics and are in fact online at https://www.ons.gov.uk/peoplepopulationandcommunity/birthsdeathsandmarriages/deaths/adho cs/undefinednumberofsuicidesanddrugpoisoningdeathsbysexandmiddlesuperoutputareasmsoase nglanddeathsregistered2012to2016. The geographic framework is provided by 6791 small areas in England, denoted as Middle Level Super Output Areas or MSOAs, which are nested within 326 Local Authorities. The aim is to establish the extent of commonalities in area risk factors between the two outcomes. The analysis focuses especially on the impacts of area deprivation, of area social fragmentation (as a proxy for neighbourhood social cohesion), and of area type (rural vs. highly urban). The model specification allows for spatially clustered but unobserved area risk factors [25].

The following sections outline the rationale for the risk factors applied to English small areas in the context of broader research evidence; consider simple bivariate associations between these risk factors and the two outcomes; and finally consider full regression models, the extent to which they show commonality in effects of risk factors, and the spatial pattern of excess relative risk. These models are fitted using the R-INLA package, which enables simplified estimation for Bayesian spatial regression [26].

\section{Area Risk Factors for Drug-Related Deaths and Suicide}

Many studies report that socio-economic deprivation and poverty are associated with higher drug misuse, drug-related mortality and increased suicide risks $[27,28]$. The impact of area deprivation is partly because it is an aggregate of individual risk factors for drug misuse and suicide, such as lower education [29], unemployment [30] and low income [31]. That is, area deprivation is partly a compositional measure of risk. However, it may also partly reflect contextual risks, or place effects per se. This shows in studies of mental illness, which, controlling for individual characteristics, show significant effects of area socioeconomic disadvantage [32,33]. The analysis below uses the UK government's Index of Multiple Deprivation (or IMD) as a score measure for area socio-economic status.

Many studies have confirmed impacts on drug misuse and suicide of neighbourhood social cohesion, which is here represented inversely by an index of social fragmentation. Low cohesion (high fragmentation) is generally proxied by available indicators such as high residential turnover [24,31], high numbers of non-family households and one person households, above average numbers of non-married adults [27,34], and absence of community institutions promoting cohesion. Impacts of neighbourhood fragmentation/cohesion on the two outcomes are to some extent simply compositional; for example, living alone and being unmarried are risk factors for both suicide [35] and drug-related death [36]. Housing type and tenure mix may also be relevant: in the UK, private sector rented housing 
is a comparatively insecure, short-stay form of housing, with Swales and Tipping [37] reporting that privately renting tenants are less likely to feel they belong to their neighbourhood or trust neighbours. The social fragmentation score used here is obtained from principal component analysis of the four variables of Congdon [34] using 2011 Census data, which measure one person and non-married households, population turnover and private sector renting.

There are variations between countries in how far drug mortality and suicide are related to urbanity, or its converse rurality, and account may need to be taken of confounding influences (including access to means) and gender differences. In the US, Ho [38] noted a convergence in drug-related deaths between rural and urban areas, whereas a rural excess remains for suicide [4]. Regarding the UK, Gartner et al. [39] reported male suicide mortality to be 11 per cent higher in rural areas after adjustment for socio-economic deprivation in 2002-2004, and more contemporary evidence shows a continuing rural excess [40].

\section{Bivariate Associations between the Outcomes and Area Risk Factors}

Some preliminary impression of the associations between the two outcomes and the area risk factors can be obtained by considering bivariate associations. Here, these are represented by tabulations of drug-related deaths (DRD) and suicide according to deciles of the deprivation score and fragmentation scores, and for urbanity, a rural-urban classification based on the 2011 Census, or RUC11 classification for short [41]. The latter is an ordered 8-fold categorisation from most to least urban, with the extremes (1st and 8th categories) being "urban major conurbation" and "rural village and dispersed in a sparse setting".

Table 1 and Figure 1 compare standard mortality ratios for drug-related deaths and suicides according to the deprivation (IMD) decile of the MSOA. It can be seen that there are regular upward gradients (increasing mortality with increased values of the risk factor) for both outcomes, but the upward gradient is sharper for drug-related deaths. The upward gradient in drug deaths is greater for males than females, with a 5.15 ratio in relative risk between the most and least deprived MSOAs for males.

Similarly, Table 2 and Figure 2 compare standard mortality ratios for drug-related deaths and suicides according to the social fragmentation decile of the MSOA. Again, these are steeper for drug deaths than suicides, with a ratio of 4 in relative male DRD risk between the most and least fragmented MSOAs. Another feature of note is the stronger upward gradient in female suicide as compared to male suicide, as social fragmentation increases.

Table 1. Drug-related deaths (DRD) and suicides, standard mortality ratios by Middle Level Super Output Area (MSOA) deprivation decile.

\begin{tabular}{ccccccc}
\hline \multirow{2}{*}{ MSOA IMD Decile } & \multicolumn{2}{c}{ Persons } & \multicolumn{2}{c}{ Males } & \multicolumn{2}{c}{ Females } \\
\cline { 2 - 7 } & DRD & Suicides & DRD & Suicides & DRD & Suicides \\
\hline IMD Decile 1 & 46 & 79 & 42 & 75 & 55 & 89 \\
IMD Decile 2 & 53 & 82 & 50 & 80 & 59 & 86 \\
IMD Decile 3 & 63 & 88 & 57 & 85 & 76 & 99 \\
IMD Decile 4 & 68 & 90 & 70 & 92 & 64 & 84 \\
IMD Decile 5 & 80 & 95 & 78 & 94 & 82 & 101 \\
IMD Decile 6 & 92 & 99 & 91 & 100 & 94 & 95 \\
IMD Decile 7 & 109 & 106 & 108 & 107 & 112 & 102 \\
IMD Decile 8 & 128 & 110 & 128 & 110 & 125 & 112 \\
IMD Decile 9 & 146 & 115 & 147 & 118 & 143 & 104 \\
IMD Decile 10 & 210 & 137 & 216 & 139 & 197 & 132 \\
\hline
\end{tabular}



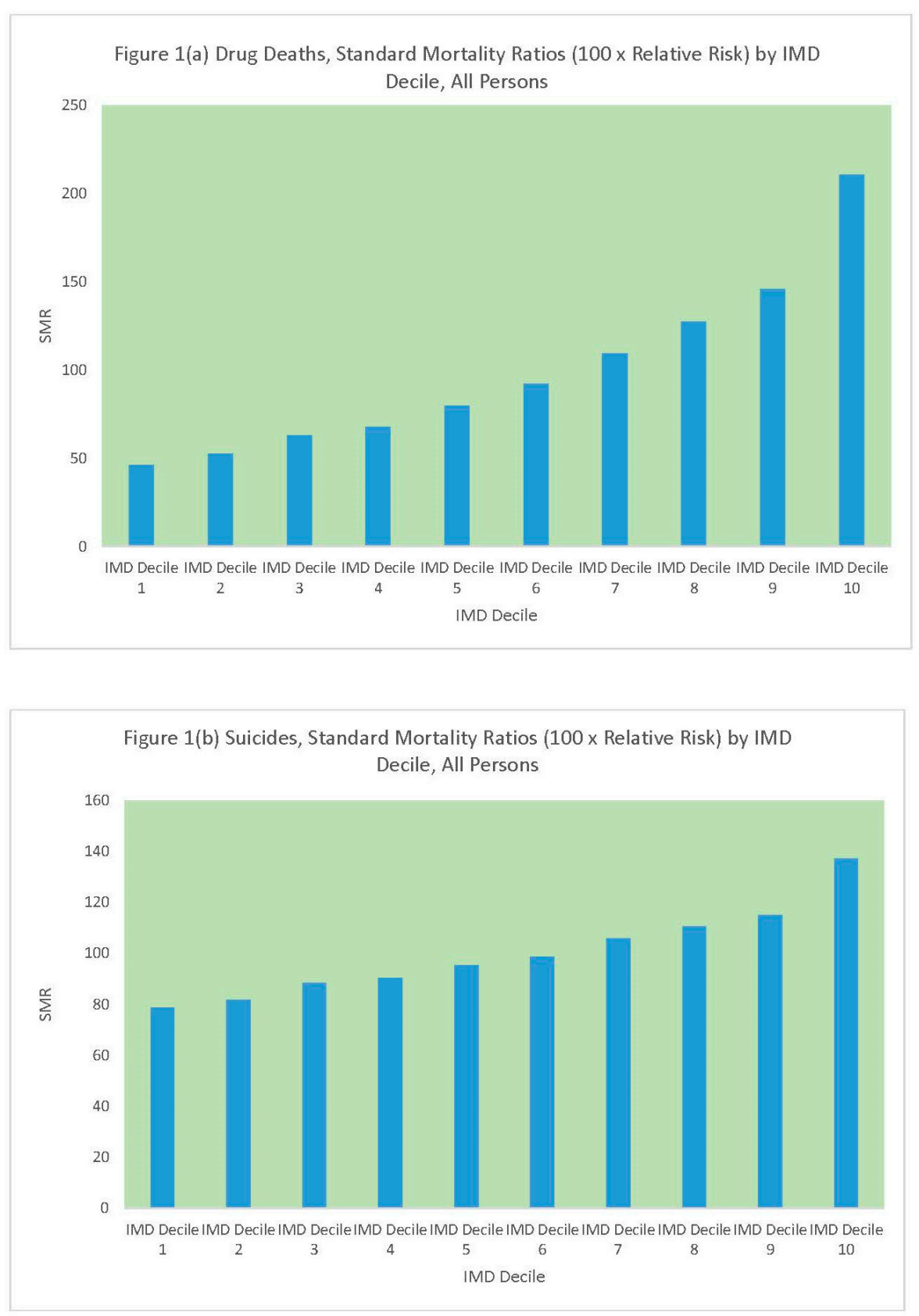

Figure 1. (a) DRD SMRs by MSOA Deprivation Decile, (b) Suicide SMRs by MSOA Deprivation Decile.

Finally, Table 3 and Figure 3 compare standard mortality ratios for drug-related deaths and suicides according to the rural-urban classification. The different categories contain differing numbers of MSOAs, with the category "urban city and town in a sparse setting" containing only 13 MSOAs. Hence, the elevated drug-related deaths standard mortality ratio for this category is representative of only a few small areas. Otherwise, the pattern for drug-related deaths seems to be of lower mortality in more rural categories, especially the categories "rural town and fringe", "rural village and dispersed", and "rural village and dispersed in a sparse setting". By contrast, suicide mortality does not fall in these categories but is comparable to that in the three most urban categories: "urban major conurbation", "urban minor conurbation", and "urban city and town". 
Table 2. Drug-related deaths (DRD) and suicides, standard mortality ratios by MSOA fragmentation decile.

\begin{tabular}{ccccccc}
\hline \multirow{2}{*}{ MSOA SFI Decile } & \multicolumn{2}{c}{ Persons } & \multicolumn{2}{c}{ Males } & \multicolumn{2}{c}{ Females } \\
\cline { 2 - 6 } & DRD & Suicides & DRD & Suicides & DRD & Suicides \\
\hline SFI Decile 1 & 47 & 80 & 43 & 81 & 57 & 79 \\
SFI Decile 2 & 53 & 81 & 50 & 81 & 58 & 81 \\
SFI Decile 3 & 60 & 86 & 59 & 85 & 63 & 87 \\
SFI Decile 4 & 72 & 92 & 71 & 92 & 76 & 92 \\
SFI Decile 5 & 83 & 96 & 80 & 98 & 90 & 91 \\
SFI Decile 6 & 100 & 105 & 98 & 106 & 104 & 99 \\
SFI Decile 7 & 117 & 108 & 120 & 109 & 114 & 103 \\
SFI Decile 8 & 130 & 112 & 130 & 112 & 130 & 113 \\
SFI Decile 9 & 138 & 116 & 134 & 116 & 143 & 117 \\
SFI Decile 10 & 173 & 119 & 172 & 114 & 158 & 136 \\
\hline
\end{tabular}
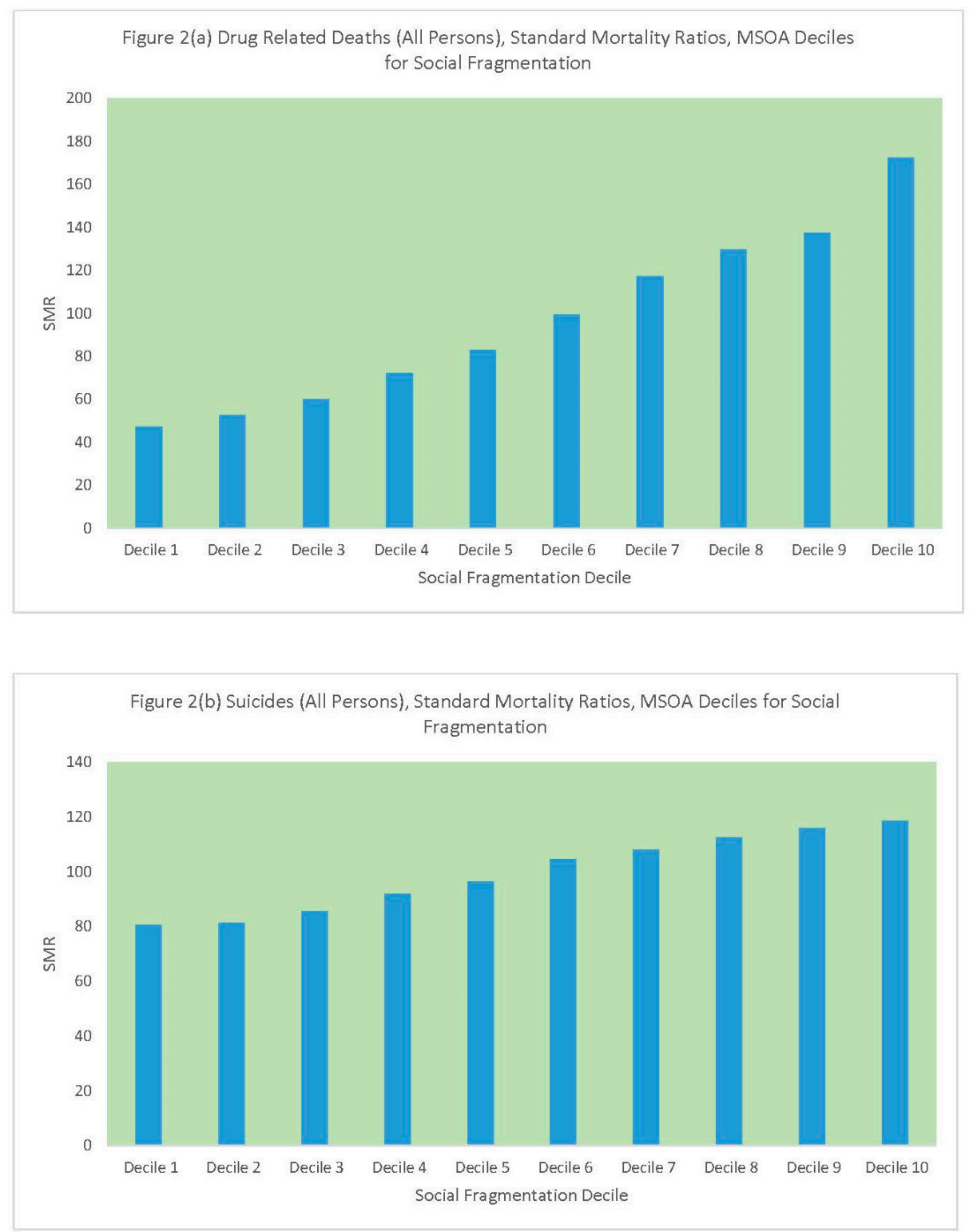

Figure 2. (a) DRD SMRs by MSOA Fragmentation Decile, (b) Suicide SMRs by MSOA Fragmentation Decile. 
Table 3. Drug-related deaths (DRD) and suicides, standard mortality ratios by rural-urban categorization (England Standard Mortality Ratio $(\mathrm{SMR})=100)$.

\begin{tabular}{cccccccc}
\hline \multirow{2}{*}{ RUC11 Category } & \multirow{2}{*}{$\begin{array}{c}\text { Number of } \\
\text { MSOAs }\end{array}$} & \multicolumn{2}{c}{ Persons } & \multicolumn{2}{c}{ Males } & \multicolumn{2}{c}{ Females } \\
\cline { 3 - 8 } & DRD & Suicides & DRD & Suicides & DRD & Suicides \\
\hline Urban major conurbation & 2399 & 97 & 92 & 96 & 93 & 99 & 90 \\
Urban minor conurbation & 249 & 111 & 99 & 112 & 100 & 106 & 94 \\
$\quad$ Urban city and town & 2938 & 114 & 108 & 115 & 107 & 113 & 110 \\
Urban city and town in a & 13 & 203 & 139 & 217 & 151 & 179 & 101 \\
$\quad \begin{array}{c}\text { sparse setting } \\
\text { Rural town and fringe }\end{array}$ & 588 & 71 & 94 & 70 & 94 & 74 & 95 \\
Rural town and fringe in a & 20 & 95 & 117 & 88 & 126 & 108 & 89 \\
$\quad \begin{array}{c}\text { sparse setting } \\
\text { Rural village and dispersed }\end{array}$ & 539 & 55 & 97 & 54 & 97 & 59 & 95 \\
Rural village and dispersed & 45 & 75 & 98 & 77 & 97 & 73 & 99 \\
$\quad$ in a sparse setting & & & & & &
\end{tabular}
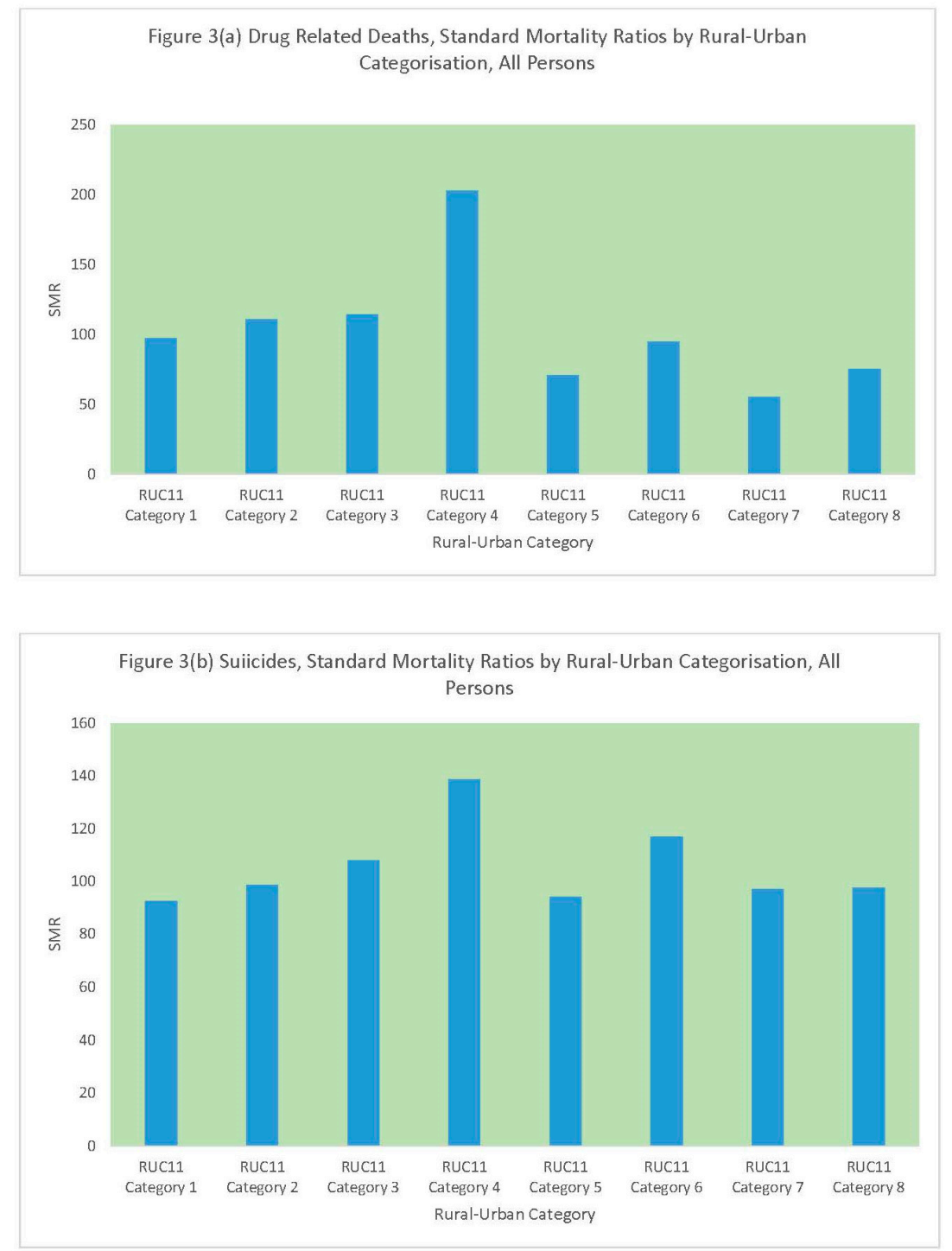

Figure 3. (a) DRD SMRs by MSOA Rural-Urban Category, (b) Suicide SMRs by MSOA Rural-Urban Category.

These bivariate associations give some indication of what a more formal regression analysis would show, but do not allow for correlations between risk factors, or for the impacts of spatially 
correlated but unobserved risk factors. For example, there is a 0.46 correlation between deprivation and fragmentation, so their impacts may be attenuated in a full regression. The next section therefore considers findings from more formal regression, with technical details of the method contained in Appendix B.

\section{Risk Factors and Relative Risks of Drug-Related Deaths and Suicides from Formal Regression}

Here, we consider how far results from formal regression match the initial impressions gained from bivariate tabulations. The large number of areas in the study raises the chance of establishing significant effects of risk factors (with $95 \%$ intervals entirely positive or negative). Table 4 shows estimates of the regression coefficients (and 95\% intervals for the coefficients) for each outcome and each risk factor. Also shown are the implied relative risks comparing neighbourhoods with extreme scores (highest and lowest scores). These can be obtained simply by exponentiating the coefficients, by virtue of the way covariates are expressed (see Appendix B): the highest deprivation and fragmentation scores have score 1 and the lowest have score 0 . The extreme contrasts in drug deaths between highly deprived and highly affluent neighbourhoods shows in relative risks approaching 10 for males.

This Table shows that deprivation and fragmentation are significant positive risk factors for both drug-related deaths and suicides, but with the regression impacts stronger for drug deaths. The fragmentation effect is highly significant despite a positive correlation between fragmentation and deprivation. Rurality has no effect on drug deaths, but there is a significant positive impact on suicides (i.e., statistically positive, meaning increased suicide in rural areas), though the impact is not nearly as strong as that of deprivation and fragmentation.

Table 4. Estimated Regression Coefficients (Drug Related Deaths and Suicides).

\begin{tabular}{|c|c|c|c|c|c|}
\hline & & Mean & $2.5 \%$ & $97.5 \%$ & $\begin{array}{c}\text { Relative Risk Comparing Areas } \\
\text { with Extreme Scores * }\end{array}$ \\
\hline \multirow[t]{10}{*}{ DRD } & Persons & & & & \\
\hline & Deprivation & 2.13 & 2.00 & 2.25 & 8.41 \\
\hline & Fragmentation & 1.78 & 1.62 & 1.94 & 5.93 \\
\hline & $\begin{array}{l}\text { Rurality } \\
\text { Males }\end{array}$ & -0.09 & -0.22 & 0.05 & 0.91 \\
\hline & Deprivation & 2.26 & 2.12 & 2.41 & 9.58 \\
\hline & Fragmentation & 1.71 & 1.53 & 1.90 & 5.53 \\
\hline & $\begin{array}{l}\text { Rurality } \\
\text { Females }\end{array}$ & -0.02 & -0.19 & 0.14 & 0.98 \\
\hline & Deprivation & 1.82 & 1.63 & 2.01 & 6.17 \\
\hline & Fragmentation & 1.53 & 1.27 & 1.78 & 4.62 \\
\hline & Rurality & 0.04 & -0.15 & 0.23 & 1.04 \\
\hline \multirow[t]{10}{*}{ Suicides } & Persons & & & & \\
\hline & Deprivation & 0.90 & 0.80 & 1.00 & 2.46 \\
\hline & Fragmentation & 0.68 & 0.55 & 0.81 & 1.97 \\
\hline & $\begin{array}{l}\text { Rurality } \\
\text { Males }\end{array}$ & 0.19 & 0.1 & 0.27 & 1.21 \\
\hline & Deprivation & 0.99 & 0.88 & 1.10 & 2.69 \\
\hline & Fragmentation & 0.53 & 0.39 & 0.68 & 1.70 \\
\hline & $\begin{array}{l}\text { Rurality } \\
\text { Females }\end{array}$ & 0.21 & 0.11 & 0.30 & 1.23 \\
\hline & Deprivation & 0.55 & 0.35 & 0.74 & 1.73 \\
\hline & Fragmentation & 1.14 & 0.89 & 1.38 & 3.13 \\
\hline & Rurality & 0.24 & 0.09 & 0.40 & 1.27 \\
\hline
\end{tabular}

* Relative Risk, Neighbourhood with Maximum Score vs Neighbourhood with Minimum Score.

To enable a more direct comparison with the preceding section, Tables 5 and 6 show estimated standard mortality ratios according to the same categories used in Tables $1-3$. Thus, Table 5 shows pronounced upward gradients in predicted drug deaths according to both deprivation and 
fragmentation. Drug-related mortality is 4.33 times more likely in the most deprived MSOAs than the least deprived, while such mortality is 3.55 times more likely in the most fragmented areas than the least. Deprivation and fragmentation tend to be lower in rural areas, and it can be seen that the categories rural town/fringe and rural village/dispersed have significantly lower drug-related deaths.

Table 6 also shows upward gradients in suicides according to both deprivation and fragmentation, albeit less pronounced than for drug deaths. For female suicides, the fragmentation gradient is steeper than that for deprivation, whereas the reverse is true for male suicides.

For suicides according to rural-urban category, possibly the most notable finding is significantly lower suicide in the most metropolitan settings (urban major conurbation), whereas the "urban city and town" categories have significantly elevated suicide mortality. Further analysis by broad English region (north, midlands, south) was undertaken (Appendix C). This shows the highest suicide SMRs to be in the "urban city and town" category in the North of England, including towns such as Blackpool, Middlesbrough, Barrow-in-Furness, Copeland and Preston, all of which have average predicted suicide SMRs (all persons) over 140.

Suicide risk in rural areas is around average in the two categories containing $94 \%$ of rural MSOAs (see Table 3), though the most sparse rural areas have excess suicide risk.

Table 5. Estimated Standard Mortality Ratios, Drug Related Deaths *.

\begin{tabular}{cccc}
\hline Deprivation & Persons & Males & Females \\
\hline IMD Decile 1 & $\mathbf{5 1 . 2}$ & $\mathbf{4 8 . 8}$ & $\mathbf{5 7 . 0}$ \\
IMD Decile 2 & $\mathbf{5 7 . 9}$ & $\mathbf{5 5 . 7}$ & $\mathbf{6 4 . 0}$ \\
IMD Decile 3 & $\mathbf{6 3 . 0}$ & $\mathbf{6 0 . 6}$ & $\mathbf{6 8 . 8}$ \\
IMD Decile 4 & $\mathbf{6 9 . 8}$ & $\mathbf{6 8 . 0}$ & $\mathbf{7 5 . 6}$ \\
IMD Decile 5 & $\mathbf{7 8 . 5}$ & $\mathbf{7 6 . 6}$ & $\mathbf{8 2 . 5}$ \\
IMD Decile 6 & $\mathbf{8 9 . 4}$ & $\mathbf{8 7 . 4}$ & $\mathbf{9 1 . 8}$ \\
IMD Decile 7 & $\mathbf{1 0 4 . 6}$ & $\mathbf{1 0 2 . 3}$ & $\mathbf{1 0 5 . 4}$ \\
IMD Decile 8 & $\mathbf{1 1 9 . 8}$ & $\mathbf{1 1 8 . 6}$ & $\mathbf{1 1 8 . 2}$ \\
IMD Decile 9 & $\mathbf{1 4 3 . 4}$ & $\mathbf{1 4 3 . 9}$ & $\mathbf{1 3 9 . 4}$ \\
IMD Decile 10 & $\mathbf{2 2 2 . 0}$ & $\mathbf{2 2 5 . 8}$ & $\mathbf{2 1 1 . 3}$ \\
Fragmentation & Persons & Males & Females \\
SFI Decile 1 & $\mathbf{5 1 . 1}$ & $\mathbf{4 9 . 0}$ & $\mathbf{5 7 . 9}$ \\
SFI Decile 2 & $\mathbf{6 0 . 9}$ & $\mathbf{5 9 . 4}$ & $\mathbf{6 7 . 3}$ \\
SFI Decile 3 & $\mathbf{6 5 . 8}$ & $\mathbf{6 4 . 5}$ & $\mathbf{7 1 . 7}$ \\
SFI Decile 4 & $\mathbf{7 4 . 4}$ & $\mathbf{7 3 . 4}$ & $\mathbf{7 9 . 1}$ \\
SFI Decile 5 & $\mathbf{8 4 . 1}$ & $\mathbf{8 3 . 1}$ & $\mathbf{8 7 . 6}$ \\
SFI Decile 6 & 98.8 & 98.0 & 100.7 \\
SFI Decile 7 & $\mathbf{1 1 6 . 2}$ & $\mathbf{1 1 6 . 5}$ & $\mathbf{1 1 4 . 9}$ \\
SFI Decile 8 & $\mathbf{1 2 9 . 9}$ & $\mathbf{1 2 9 . 8}$ & $\mathbf{1 2 7 . 5}$ \\
SFI Decile 9 & $\mathbf{1 3 7 . 0}$ & $\mathbf{1 3 5 . 1}$ & $\mathbf{1 3 4 . 5}$ \\
SFI Decile 10 & $\mathbf{1 8 1 . 4}$ & $\mathbf{1 7 8 . 8}$ & $\mathbf{1 7 2 . 8}$ \\
Urban-Rural Category ** & Persons & Males & Females \\
Urban major conurbation & 100.0 & $\mathbf{9 8 . 5}$ & $\mathbf{1 0 4 . 1}$ \\
Urban minor conurbation & $\mathbf{1 1 4 . 0}$ & $\mathbf{1 1 5 . 8}$ & $\mathbf{1 0 9 . 3}$ \\
Urban city/town & $\mathbf{1 1 0 . 5}$ & $\mathbf{1 0 8 . 8}$ & $\mathbf{1 0 8 . 2}$ \\
Urban city/town (sparse) & $\mathbf{1 6 5 . 6}$ & $\mathbf{1 6 6 . 7}$ & $\mathbf{1 4 4 . 4}$ \\
Rural town/fringe & $\mathbf{7 2 . 7}$ & $\mathbf{7 2 . 5}$ & $\mathbf{7 8 . 3}$ \\
Rural town/fringe (sparse) & 98.5 & 98.5 & 106.7 \\
Rural village/dispersed & $\mathbf{6 5 . 0}$ & $\mathbf{6 4 . 9}$ & $\mathbf{7 2 . 9}$ \\
Rural village/dispersed (sparse) & 93.5 & 95.2 & 99.7 \\
\hline & & & \\
\hline
\end{tabular}

* Significantly Elevated or Depressed SMRs in Bold, ${ }^{* *}$ For full category names see Table 3. 
Table 6. Estimated Standard Mortality Ratios, Suicides*.

\begin{tabular}{|c|c|c|c|}
\hline Deprivation & Persons & Males & Females \\
\hline IMD Decile 1 & 78.2 & 77.0 & 82.0 \\
\hline IMD Decile 2 & 83.9 & 83.1 & 86.9 \\
\hline IMD Decile 3 & 87.9 & 87.0 & 91.0 \\
\hline IMD Decile 4 & 91.6 & 90.9 & 94.3 \\
\hline IMD Decile 5 & 94.7 & 94.0 & 97.3 \\
\hline IMD Decile 6 & 98.8 & 98.4 & 100.1 \\
\hline IMD Decile 7 & 103.9 & 103.6 & 105.1 \\
\hline IMD Decile 8 & 108.3 & 108.4 & 107.9 \\
\hline IMD Decile 9 & 116.4 & 118.0 & 111.7 \\
\hline IMD Decile 10 & 138.4 & 142.2 & 126.6 \\
\hline Fragmentation & Persons & Males & Females \\
\hline SFI Decile 1 & 80.5 & 80.9 & 79.4 \\
\hline SFI Decile 2 & 86.6 & 87.1 & 85.8 \\
\hline SFI Decile 3 & 89.7 & 90.0 & 89.2 \\
\hline SFI Decile 4 & 93.6 & 94.2 & 91.9 \\
\hline SFI Decile 5 & 96.8 & 97.7 & 94.3 \\
\hline SFI Decile 6 & 102.4 & 103.1 & 99.4 \\
\hline SFI Decile 7 & 108.2 & 109.2 & 104.5 \\
\hline SFI Decile 8 & 111.7 & 112.3 & 108.9 \\
\hline SFI Decile 9 & 110.7 & 109.9 & 113.0 \\
\hline SFI Decile 10 & 121.8 & 117.9 & 136.6 \\
\hline Urban-Rural Category ** & Persons & Males & Females \\
\hline Urban major conurbation & 93.7 & 94.4 & 92.5 \\
\hline Urban minor conurbation & 100.6 & 103.6 & 92.2 \\
\hline Urban city/town & 105.8 & 105.0 & 107.3 \\
\hline Urban city/town (sparse) & 133.4 & 134.9 & 126.3 \\
\hline Rural town/fringe & 97.9 & 98.2 & 98.9 \\
\hline Rural town/fringe (sparse) & 113.3 & 113.7 & 117.3 \\
\hline Rural village/dispersed & 98.1 & 98.4 & 99.4 \\
\hline Rural village/dispersed (sparse) & 115.6 & 116.8 & 117.8 \\
\hline
\end{tabular}

* Significantly Elevated or Depressed SMRs in Bold, ${ }^{* *}$ For full category names see Table 3.

\section{Concentrated Excess Risk}

A notable feature of the distribution of excess risk at MSOA level, especially for drug-related deaths, is the marked concentration of excess risk. This has implications for targeted public health interventions.

Thus, Table 7 shows the 20 MSOAs with the highest predicted relative risk of drug-related death (all persons). It can be seen that five of the 20 are from one local authority, namely Blackpool. Map representation of Blackpool and two adjacent local authorities shows the clustering of extremely elevated DRD risk (Figure 4), with relative risks exceeding 10 in two MSOAs. The latter MSOAs are adjacent coastal MSOAs in Blackpool. The excess risk in these MSOAs contrasts with a background of lower than average risk in eastern MSOAs in the region mapped.

A distinguishing feature of the MSOAs in Table 7 is that they are all in the most deprived and fragmented deciles, confirming the strong relevance of these two risk factors to explaining DRD spatial contrasts.

As to suicide contrasts, the MSOAs with the highest predicted relative risks (all persons) are shown in Table 8. As for drug deaths, these MSOAs are also in the most fragmented and deprived deciles. However, the most extreme excess risks are less pronounced than for drug deaths, reaching only 2.8. Four of the highest suicide relative risks are in Blackpool, and comparison of Figures 4 and 5 (for neighbourhoods in Blackpool and two adjacent local authorities) shows a spatial overlap in suicide and DRD excess risk. 
Table 7. MSOAs with Highest DRD Relative Risk, With Socio-Economic and Locational Details.

\begin{tabular}{|c|c|c|c|c|c|}
\hline \multirow[b]{2}{*}{ MSOA Name } & \multirow[b]{2}{*}{ Local Authority } & \multirow[b]{2}{*}{ Region } & \multicolumn{3}{|c|}{ Relative Risk (95\% Interval) } \\
\hline & & & Mean & $2.5 \%$ & $97.5 \%$ \\
\hline Blackpool 010 & Blackpool & North West & 11.67 & 8.60 & 15.31 \\
\hline Blackpool 013 & Blackpool & North West & 11.26 & 7.68 & 15.61 \\
\hline Blackpool 006 & Blackpool & North West & 9.22 & 6.36 & 12.72 \\
\hline Tendring 016 & Tendring & East of England & 7.71 & 4.95 & 11.20 \\
\hline Blackpool 008 & Blackpool & North West & 7.57 & 5.15 & 10.56 \\
\hline Wirral 016 & Wirral & North West & 6.23 & 4.47 & 8.39 \\
\hline Thanet 001 & Thanet & South East & 6.15 & 4.04 & 8.75 \\
\hline Great Yarmouth 006 & Great Yarmouth & East of England & 5.88 & 3.94 & 8.28 \\
\hline Sunderland 016 & Sunderland & North East & 5.73 & 3.83 & 8.10 \\
\hline Blackpool 007 & Blackpool & North West & 5.67 & 3.67 & 8.25 \\
\hline Shepway 014 & Shepway & South East & 5.64 & 3.40 & 8.52 \\
\hline Middlesbrough 003 & Middlesbrough & North East & 5.43 & 3.66 & 7.63 \\
\hline Sefton 004 & Sefton & North West & 5.43 & 3.75 & 7.52 \\
\hline Stockton-on-Tees 014 & Stockton-on-Tees & North East & 5.26 & 3.94 & 6.84 \\
\hline Hastings 011 & Hastings & South East & 5.23 & 3.41 & 7.52 \\
\hline Plymouth 029 & Plymouth & South West & 5.18 & 3.59 & 7.13 \\
\hline Barrow-in-Furness 008 & Barrow-in-Furness & North West & 5.17 & 3.24 & 7.67 \\
\hline Weymouth and Portland 004 & Weymouth and Portland & South West & 5.00 & 3.25 & 7.20 \\
\hline Waveney 007 & Waveney & East of England & 4.93 & 3.24 & 7.07 \\
\hline Burnley 007 & Burnley & North West & 4.84 & 3.09 & 7.14 \\
\hline
\end{tabular}

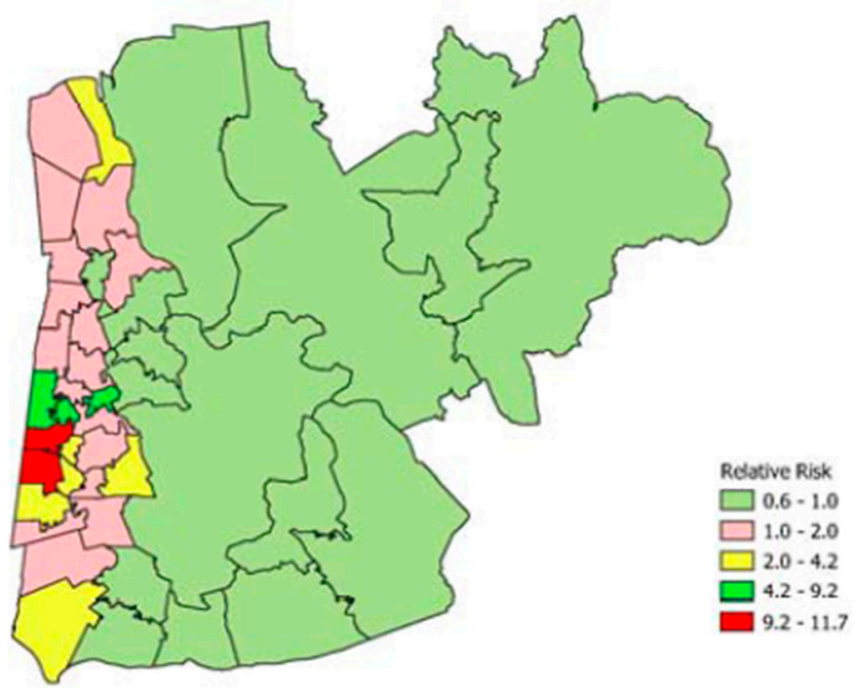

Figure 4. Drug-related death risk by MSOA (Blackpool, Fylde, Wyre).

In fact, across all 6791 English MSOAs, the correlation between DRD and suicide relative risks is 0.965. Interpreting this is subject to the caveat that the two events are not completely independent, since around a fifth of drug-related death figures are classified as suicides (method: drug overdose, or poisoning), and, conversely, a sixth of suicides are drug-related; see Appendix A [22,23]. However, the definitional overlap is unlikely to account for all this correlation. 
Table 8. MSOAs with Highest Suicide Relative Risk, With Socio-Economic and Locational Details.

\begin{tabular}{cccccc}
\hline MSOA Name & Local Authority & Region & Mean & $\mathbf{2 . 5 \%}$ & $\mathbf{9 7 . 5 \%}$ \\
\hline Blackpool 013 & Blackpool & North West & 2.80 & 2.02 & 3.76 \\
Thanet 001 & Thanet & South East & 2.76 & 1.96 & 3.74 \\
Tendring 016 & Tendring & East of England & 2.74 & 1.93 & 3.75 \\
Blackpool 010 & Blackpool & North West & 2.71 & 2.09 & 3.46 \\
Torbay 008 & Torbay & South West & 2.48 & 1.84 & 3.26 \\
Cornwall 068 & Cornwall & South West & 2.43 & 1.56 & 3.55 \\
Hastings 011 & Hastings & South East & 2.42 & 1.75 & 3.24 \\
Middlesbrough 003 & Middlesbrough & North East & 2.36 & 1.79 & 3.06 \\
Blackpool 006 & Blackpool & North West & 2.34 & 1.73 & 3.08 \\
Great Yarmouth 006 & Great Yarmouth & East of England & 2.33 & 1.71 & 3.09 \\
Barrow-in-Furness 008 & Barrow-in-Furness & North West & 2.30 & 1.63 & 3.14 \\
Blackpool 008 & Blackpool & North West & 2.23 & 1.65 & 2.93 \\
Middlesbrough 002 & Middlesbrough & North East & 2.19 & 1.68 & 2.80 \\
Kingston upon Hull 024 & Kingston upon Hull & Yorkshire \& Humberside & 2.17 & 1.70 & 2.73 \\
Shepway 014 & Shepway & South East & 2.17 & 1.42 & 3.14 \\
Sefton 004 & Sefton & North West & 2.15 & 1.66 & 2.75 \\
Stockton-on-Tees 014 & Stockton-on-Tees & North East & 2.14 & 1.75 & 2.60 \\
Middlesbrough 001 & Middlesbrough & North East & 2.13 & 1.75 & 2.56 \\
Lancaster 009 & Lancaster & North West & 2.10 & 1.49 & 2.86 \\
Brighton and Hove 030 & Brighton and Hove & South East & 2.09 & 1.56 & 2.73 \\
\hline
\end{tabular}

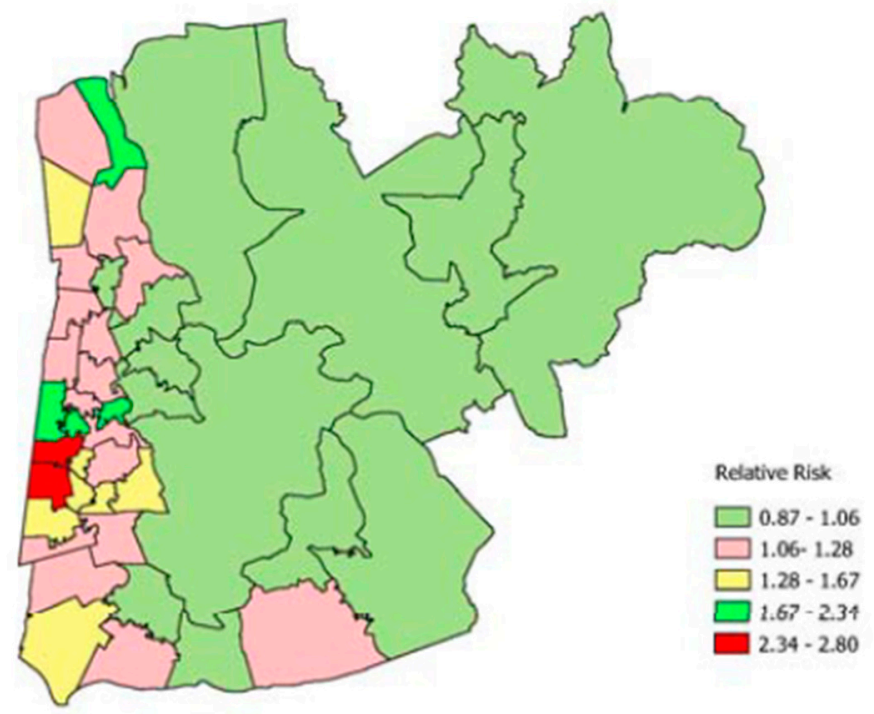

Figure 5. Suicide risk by MSOA (Blackpool, Fylde, Wyre).

\section{Compositional vs. Contextual Effects}

As for all health outcomes, a multilevel study considering area and individual risk factors in tandem may be regarded as the ideal, especially as there remains some debate about the existence of distinct area effects. In connection with that debate, one may say that many multilevel studies have a restricted geographic focus (e.g., on health variations within a city), not providing a proper comparative evaluation of area effects, and may not consider how contextual factors (e.g., changing local housing market opportunities) affect residential location of vulnerable groups at higher risk of (for example) drug-related deaths. Ecological (area-based) studies can have considerably greater coverage than multilevel studies. Thus, the present study is based on recent evidence comparing small areas across all of England and its nine regions.

Multilevel studies of psychiatric illnesses such as depression (which are risk factors for drug dependence and suicidality) have found contextual effects after control for individual risk factors. Thus, the authors of [33] mention "the daily stress of living in a neighborhood where residential 
mobility and material deprivation prevail is associated with depression [after control for individual attributes]". Another study [42] finds a protective effect for low income people living in affluent areas. A multilevel study of suicide carried out by $\mathrm{O}^{\prime}$ Reilly et al. [43] finds area effects to be absent after control for individual risk factors, but arguably provides only a relatively restricted intra-regional comparison (Northern Ireland), for an adult population of 1.6 million.

A broader comparison enables more complete evaluation of the impacts of local and regional labour markets, and of local and regional housing markets, which can be considered as primarily contextual factors. In that regard, the present study across enables a broader and more comprehensive assessment of relative risk differences across all nine English regions. It remains true that the present study is a population-based or ecological study [42], and "such studies cannot determine whether these are area effects (context) or due to the characteristics of the people living in these areas (composition)" [43].

However, the broad national scale of the present study means that some of the differences in relative risk identified may be plausibly linked to different housing and economic opportunities between and within regions. These may affect the residential location of at risk groups, and so reflect an interaction between contextual and individual risk factors.

For example, a recent House of Lords report on social and health problems in British coastal towns [44] mentions that "[a] decline in tourism, [has] left many seaside towns with a legacy of redundant tourist accommodation, including former hotels and bed and breakfast properties. Many of these properties [have been] converted to cater for the private rental market, leading to a dramatic growth in the number of HMOs [houses in multiple occupation] in seaside towns." Such housing is often of low quality, attracting transient and vulnerable groups often living on state welfare support, and these changes adversely affect social cohesion. The operation of local housing factors in the rental market can be considered as a contextual influence, and its impact on the location of transient vulnerable groups may partly explain the extremely high rates of drug and suicide deaths in some MSOAs in Blackpool and other coastal towns. Thus, the highest relative risks for drug deaths (see Tables 7 and 8) include an over-representation of neighbourhoods in coastal towns such as Blackpool, Clacton, Torbay, Hastings, Weymouth, Great Yarmouth and Brighton.

\section{Conclusions}

There are a number of small area studies of drug-related deaths and suicides. There have been more studies for both outcomes in the US, whereas in the UK there have been many more small area studies of suicide than of drug-related deaths.

A limitation of the present study is that it is ecological (area-based), so one cannot determine whether effects of area risk factors are due to context, or the characteristics of the people living in these areas (composition). However, as a counterbalance is the comprehensive coverage obtained of spatial variations in the two events, across all English small areas. The disaggregation of event counts by gender has shown gender differences in covariate effects. An additional strength is provided by a comparison of outcomes. No previous UK studies have compared the two outcomes for comparable time and spatial frameworks. The present study is therefore distinctive in carrying out a comparative small area study of the spatial patterning of drug deaths and suicides, which are two mortality types now often grouped under the umbrella category of "deaths of despair" [6,45]. A further strength is consideration of the impacts of deprivation and fragmentation in tandem: no previous small area study of UK drug deaths has considered social cohesion or fragmentation as a risk factor.

Future research on small area differences might consider outcome counts disaggregated by broad age group (e.g., young adults under 44 versus other age bands) as impacts of area risk factors may be age- as well as gender-differentiated. There is also scope to compare suicide, drug-related deaths and alcohol-related deaths, namely all components of deaths of despair.

As to findings of the present study, some contrasts between the outcomes are revealed: thus, drug-related deaths are distinct in showing extremely high relative risks in some MSOAs. However, the comparative analysis has shown commonalities, such as a considerable similarity in the spatial 
patterning of the two events. There is also strong similarity in the area risk factors for drug-related deaths and suicides, with particular regard to the impacts of deprivation and social fragmentation.

The impacts of these two risk factors are significantly positive for both outcomes, but the impacts are stronger for drug deaths. Whereas a number of existing studies have shown social fragmentation to be a significant positive risk factor for suicide, the present paper is the first showing that there is a strong impact of social fragmentation on drug-related deaths also.

Of relevance to interpreting these contrasts are the misclassification issue mentioned in the Introduction (nominally accidental drug deaths are in fact suicide), and also the outcome definitional overlap (see Appendix A). It has been suggested that the potential for misclassification is greater among women [46], since "the less immediately lethal methods of suicide preferred by women, such as self-poisoning, are more likely to be mis-classified as accidental than the more immediately lethal methods of suicide preferred by men".

Thus, the deprivation and fragmentation effects identified by regression in the paper are stronger for drug-related deaths than for suicides, as officially defined. However, to the extent that drug-related deaths are concealed suicides, it may be that the deprivation and fragmentation effects for suicides are understated, and this understatement is more likely for females. It could also be suggested that the reason that drug-related deaths may show a stronger correlation with deprivation, compared to suicide deaths, is due to social stigma, making drug misuse deaths more prevalent or visible in more deprived areas. It might also be suggested that stronger deprivation and fragmentation effects for drug-related deaths reflect higher levels of illicit drug misuse in more deprived areas, as opposed to prescription drug misuse.

Gender differences in impacts of area covariates are apparent from the regressions, and raise potential questions regarding the relative impact of 'gendered' risk factors. Thus, for female suicides, the fragmentation gradient is steeper than that for deprivation, whereas the reverse is true for male suicides. Such findings are consistent with differential gender risk factor effects: for example, loss of employment may be more strongly related to masculine despair, whereas loss of social support and lower social integration are more strongly related to feminine despair [47-49]. Thus, the authors of [50] mention that "the relationship between unemployment and suicide, and socio-economic status and suicide, appears to be stronger for men than it is for women. Overall, then, men are more sensitive to negative changes in their socio-economic and employment status, and this may lead to higher risks for suicide".

Implications for public health intervention of the findings here may be considered. Thus, highly localised excess risks of both events, but especially drug-related deaths, point to the need for local neighbourhood targeting of interventions. The HM Government's drug strategy [51] mentions "a targeted approach for high priority groups", and "targeting the most vulnerable", and this approach may need to take into account how housing or labour market factors lead to concentration of vulnerable groups in particular neighbourhoods. Similarly, the findings here support targeted suicide interventions, in line with [52], which proposes that interventions "should recognise the strong association between suicidal behaviour and area-level socioeconomic deprivation, targeting efforts on both people and places." Deciding which areas have highest priority for prevention measures is often based on socioeconomic scoring procedures, and the findings here point to the need to consider social fragmentation (as an inverse index of social cohesion) as well as area deprivation.

Funding: This research received no external funding.

Conflicts of Interest: The authors declare no conflict of interest.

\section{Appendix A. Definition of Outcomes by ICD and Overlap Due to Drug-Related Suicides}

Deaths related to drugs are for underlying causes defined by International Classification of Diseases, Ninth and Tenth Revisions (ICD-9 and ICD-10) codes: 


\begin{tabular}{ccc}
\hline Description & ICD-9 Codes & ICD-10 Codes \\
\hline $\begin{array}{c}\text { Mental and behavioural disorders due to drug use } \\
\text { (excluding alcohol and tobacco) }\end{array}$ & 292, 304, 305.2-305.9 & F11-F16, F18-F19 \\
Accidental poisoning by drugs, medicaments and biological \\
$\begin{array}{c}\text { substances } \\
\text { Intentional self-poisoning by drugs, medicaments and } \\
\text { biological substances }\end{array}$ & E850-E858 & X40-X44 \\
$\begin{array}{c}\text { Assault by drugs, medicaments and biological substances } \\
\text { Poisoning by drugs, medicaments and biological substances, } \\
\text { undetermined intent }\end{array}$ & E980.0-E980.5 & X60-X64 \\
\hline
\end{tabular}

Deaths due to suicide are defined as deaths with an underlying cause of intentional self-harm or injury/poisoning of undetermined intent, with ICD-10 codes:

\begin{tabular}{cc}
\hline ICD-10 Codes & Description \\
\hline X60-X84 & Intentional self-harm \\
Y10-Y34 & Injury/poisoning of undetermined intent \\
\hline
\end{tabular}

There is an overlap between the outcomes. The overlap arises from intentional self-poisoning by drugs, medicaments and biological substances (ICD X60-X64), and poisoning by drugs, medicaments and biological substances, undetermined intent (Y10-Y14); these are an element in both suicides and drug deaths. Thus, for the years 2015-2017, and across all England, there were 13,846 suicides, of which 2316 (16.7\%) were drug-related suicides (ICD10 X60-X64, Y10-Y14); the percentage drug-related is higher for females (31.4\%) than for males (11.8\%). In the same period, there were 10,348 drug-related deaths, of which $22.4 \%$ were drug-related suicides; the percentage is higher for females $(33 \%)$ than males $(17.4 \%)$.

\section{Appendix B. Regression Methods}

The method used in this paper is widely adopted in applications usually described as Bayesian disease mapping [53]. Specifically, we used a form of generalised linear model to estimate relative risks for the two outcomes, with the model incorporating an assumption (a prior belief) that there is likely to be correlation between risk in areas geographically close. For both outcomes, the response is a count variable and the outcome is relatively rare, so a Poisson log-linear model is assumed based on known risk factors $X$ (e.g., deprivation) and including a spatially structured error term. So for counts $Y_{i}$ of a particular outcome in area $i$ (for example, drug deaths) we have

$$
\begin{aligned}
& Y_{i} \sim \operatorname{Poisson}\left(E_{i} \rho_{i}\right), \\
& \log \left(\rho_{i}\right)=X_{i} \beta+v_{i},
\end{aligned}
$$

where $E_{i}$ are expected drug deaths, $\rho_{i}$ is the relative risk of DRD for area i, $\beta$ are regression coefficients for known risk factors $X_{i}$, and $v_{i}$ is a random effect representing unexplained spatial correlation. These random effects are assumed to follow a conditional autoregressive distribution, as developed by Besag et al. [54], with the spatial effect for area i depending on spatial effects in adjacent areas. Also following Besag et al. [54], we include a spatially independent random effect $u_{i}$ to represent geographically unstructured heterogeneity in disease risk. Then the log-linear model for relative risk is

$$
\log \left(\rho_{\mathrm{i}}\right)=\mathrm{X}_{\mathrm{i}} \beta+v_{\mathrm{i}}+\mathrm{u}_{\mathrm{i}}
$$

Estimation of the models is carried out using the R-INLA package. In the regression, we represent the risk factors IMD and social fragmentation in $(0,1)$ form, so that the highest deprivation and 
fragmentation scores have score 1 and the lowest have score 0 . Putting risk factors on the same scale in this way means the relative importance of their impacts can be assessed. To represent urban-rural status, a ridit score of rurality is obtained based on the ordered $2011 \mathrm{rural} /$ urban categories [55]. This score is in $(0,1)$ form by definition, with 1 representing the most rural areas. This scoring approach is adopted to avoid potentially unstable estimates if a categorical predictor were used instead, since some categories have small numbers of MSOAs in them.

\section{Appendix C. Grouping of Regions}

We grouped the nine standard regions of England into three broader groupings as follows:

\begin{tabular}{|c|c|}
\hline Standard Region & Broad Category \\
\hline East Midlands & Midlands \\
\hline East of England & Midlands \\
\hline London & South \\
\hline North East & North \\
\hline North West & North \\
\hline South East & South \\
\hline South West & South \\
\hline West Midlands & Midlands \\
\hline Yorkshire and The Humber & North \\
\hline
\end{tabular}

\section{References}

1. Kochanek, K.D.; Murphy, S.; Xu, J.; Arias, E. Mortality in the United States; NCHS Data Brief No. 293; National Center for Health Statistics: Washington DC, USA, 2016.

2. Rossen, L.M.; Khan, D.; Warner, M. Trends and Geographic Patterns in Drug-Poisoning Death Rates in the U.S., 1999-2009. Am. J. Prev. Med. 2013, 45, e19-e25. [CrossRef] [PubMed]

3. European Monitoring Centre for Drugs and Drug Addiction. The European Drug Report 2018: Trends and Developments; EMCDDA: Lisbon, Portugal, 2018.

4. Rossen, L.M.; Hedegaard, H.; Khan, D.; Warner, M. County-Level Trends in Suicide Rates in the U.S., 2005-2015. Am. J. Prev. Med. 2018, 55, 72-79. [CrossRef] [PubMed]

5. Nakar, O.; Brunner, R.; Schilling, O.; Chanen, A.; Fischer, G.; Parzer, P.; Carli, V.; Wasserman, D.; Sarchiapone, M.; Wasserman, C.; et al. Developmental trajectories of self-injurious behavior, suicidal behavior and substance misuse and their association with adolescent borderline personality pathology. J. Affect. Disord. 2016, 197, 231-238. [CrossRef]

6. Case, A.; Deaton, A. Mortality and Morbidity in the 21st Century. Brook. Pap. Econ. Act. 2017, 2017, $397-476$. [CrossRef]

7. Al-Sharqi, A.M.; Sherra, K.S.; Al-Habeeb, A.A.; Qureshi, N.A. Suicidal and self-injurious behavior among patients with alcohol and drug abuse. Subst. Abus. Rehabil. 2012, 3, 91-99.

8. Rockett, I.R.H.; Caine, E.D.; Connery, H.S.; Greenfield, S.F. Mortality in the United States from self-injury surpasses diabetes: A prevention imperative. Inj. Prev. 2018, in press.

9. Stone, D.M.; Holland, K.M.; Bartholow, B.; ELogan, J.; LiKamWa McIntosh, W.; Trudeau, A.; Rockett, I.R. Deciphering suicide and other manners of death associated with drug intoxication. Am. J. Public Health 2017, 107, 1233-1239. [PubMed]

10. Gray, D.; Coon, H.; McGlade, E.; Callor, W.B.; Byrd, J.; Viskochil, J.; Bakian, A.; Yurgelun-Todd, D.; Grey, T.; McMahon, W.M.; et al. Comparative Analysis of Suicide, Accidental, and Undetermined Cause of Death Classification. Suicide Life-Threat. Behav. 2014, 44, 304-316. [CrossRef] [PubMed]

11. Duncan, C.; Jones, K.; Moon, G. Context, composition and heterogeneity: Using multilevel models in health research. Soc. Sci. Med. 1998, 46, 97-117. [CrossRef] 
12. Kwan, M.; Peterson, R.; Browning, C.; Burrington, L.; Calder, C.; Krivo, L. Reconceptualizing sociogeographic context for the study of drug use, abuse, and addiction. In Geography and Drug Addiction; Springer: Dordrecht, The Netherlands, 2008; pp. 437-446.

13. Collins, J.; Ward, B.; Snow, P.; Kippen, S.; Judd, F. Compositional, contextual, and collective community factors in mental health and well-being in Australian rural communities. Qual. Health Res. 2017, 27, 677-687. [CrossRef]

14. Kawachi, I.; Berkman, L. (Eds.) Social cohesion, social capital, and health. In Social Epidemiology; OUP: Oxford, UK, 2000.

15. DiMaggio, C.; Bucciarelli, A.; Tardiff, K.; Vlahov, D.; Galea, S. Spatial Analytic Approaches to Explaining the Trends and Patterns of Drug Overdose Deaths. In Geography and Drug Addiction; Thomas, Y., Richardson, D., Cheung, I., Eds.; Springer: Dordrecht, The Netherlands, 2008.

16. Ghertner, R.; Groves, L. The Opioid Crisis and Economic Opportunity: Geographic and Economic Trends; ASPE Research Brief; U.S. Department of Health and Human Services: Washington DC, USA, 2018.

17. Griffiths, C.; Romeri, E.; Brock, A.; Morgan, O. Geographical variations in deaths related to drug misuse in England and Wales, 1993-2006. Health Stat. Q. 2008, 39, 14.

18. Zoorob, M.J.; Salemi, J.L. Bowling alone, dying together: The role of social capital in mitigating the drug overdose epidemic in the United States. Drug Alcohol Depend. 2017, 173, 1-9. [CrossRef]

19. Gunnell, D.J.; Peters, T.J.; Kammerling, R.M.; Brooks, J. Relation between parasuicide, suicide, psychiatric admissions, and socioeconomic deprivation. BMJ 1995, 311, 226-230. [CrossRef]

20. Qi, X.; Hu, W.; Mengersen, K.; Tong, S. Socio-environmental drivers and suicide in Australia: Bayesian spatial analysis. BMC Public Health 2014, 14, 681. [CrossRef]

21. Office of National Statistics. User Guide to Mortality Statistics; ONS: London, UK, 2018. Available online: https://www.ons.gov.uk/peoplepopulationandcommunity/birthsdeathsandmarriages/deaths/ methodologies/userguidetomortalitystatisticsjuly2017\#certification-of-cause-of-death (accessed on 17 May 2019).

22. Office of National Statistics. Deaths Related to Drug Poisoning in England and Wales: 2017 Registrations. Deaths Related to Drug Poisoning in England and Wales from 1993 Onwards, by Cause of Death, Sex, Age and substances INVOLVED in the Death; ONS Statistical Bulletin; ONS: London, UK, 2018.

23. Office of National Statistics. Suicides in the UK: 2017 Registrations; ONS Statistical Bulletin; ONS: London, UK, 2018.

24. Ajdacic-Gross, V.; Weiss, M.G.; Ring, M.; Hepp, U.; Bopp, M.; Gutzwiller, F.; Rössler, W. Methods of suicide: International suicide patterns derived from the WHO mortality database. Bull. World Health Organ. 2008, 86, 726-732. [CrossRef] [PubMed]

25. Best, N.; Arnold, N.; Thomas, A.; Waller, L.; Conlon, E. Bayesian models for spatially correlated disease and exposure data. In Bayesian Statistics 6: Proceedings of the Sixth Valencia International Meeting; Clarendon Press: Wotton-under-Edge, UK, 1999; Volume 6, p. 131.

26. Moraga, P. Small Area Disease Risk Estimation and Visualization Using R. R J. 2018, 10, 495-506. [CrossRef]

27. Monnat, S.M. Factors Associated With County-Level Differences in U.S. Drug-Related Mortality Rates. Am. J. Prev. Med. 2018, 54, 611-619. [CrossRef]

28. Kerr, W.; Kaplan, M.; Huguet, N.; Caetano, R.; Giesbrecht, N.; McFarland, B. Economic recession, alcohol, and suicide rates: Comparative effects of poverty, foreclosure, and job loss. Am. J. Prev. Med. 2017, 52, 469-475. [CrossRef]

29. Ho, J.Y. The Contribution of Drug Overdose to Educational Gradients in Life Expectancy in the United States, 1992-2011. Demography 2017, 54, 1175-1202. [CrossRef]

30. Blakely, T.; Collings, S.; Atkinson, J. Unemployment and suicide. Evidence for a causal association? J. Epidemiol. Community Health 2003, 57, 594-600. [CrossRef]

31. Sareen, J.; Afifi, T.; McMillan, K.; Asmundson, G. Relationship between Household Income and Mental Disorders: Findings from a Population-Based Longitudinal Study. Arch. Gen. Psychiatry 2011, 68, 419-427. [CrossRef] [PubMed]

32. Silver, E.; Mulvey, E.P.; Swanson, J.W. Neighborhood structural characteristics and mental disorder: Faris and Dunham revisited. Soc. Sci. Med. 2002, 55, 1457-1470. [CrossRef]

33. Matheson, F.I.; Moineddin, R.; Dunn, J.R.; Creatore, M.I.; Gozdyra, P.; Glazier, R.H. Urban neighborhoods, chronic stress, gender and depression. Soc. Sci. Med. 2006, 63, 2604-2616. [CrossRef] 
34. Congdon, P. Suicide and Parasuicide in London: A Small-area Study. Urban Stud. 1996, 33, 137-158. [CrossRef]

35. Purcell, B.; Heisel, M.J.; Speice, J.; Franus, N.; Conwell, Y.; Duberstein, P.R. Family Connectedness Moderates the Association between Living Alone and Suicide Ideation in a Clinical Sample of Adults 50 Years and Older. Am. J. Geriatr. Psychiatry 2012, 20, 717-723. [CrossRef] [PubMed]

36. Office of National Statistics. Drug-Related Deaths "Deep Dive" into Coroners' Records; ONS: London, UK, 2018.

37. Swales, K.; Tipping, S. Fragmented Communities? The Role of Cohesion, Community Involvement and Social Mixing; NatCen Social Research: London, UK, 2018.

38. Ho, J.Y. The Contemporary American Drug Overdose Epidemic in International Perspective. Popul. Dev. 2019, 45, 7-40. [CrossRef]

39. Gartner, A.; Farewell, D.; Dunstan, F.; Gordon, E. Differences in mortality between rural and urban areas in England and Wales, 2002-04. Health Stat. Q. 2008, 39, 6.

40. Local Government Association/Public Health England. Health and Wellbeing in Rural Areas; Local Government Association: London, UK, 2017.

41. Bibby, P.; Brindley, P. The 2011 Rural-Urban Classification for Small Area Geographies: A User Guide; UK Government Statistical Service: London, UK, 2013.

42. Astell-Burt, T.; Feng, X. Investigating 'place effects' on mental health: Implications for population-based studies in psychiatry. Epidemiol. Psychiatr. Sci. 2015, 24, 27-37. [CrossRef]

43. O'Reilly, D.; Rosato, M.; Connolly, S.; Cardwell, C. Area factors and suicide: 5-year follow-up of the Northern Ireland population. Br. J. Psychiatry 2008, 192, 106-111. [CrossRef]

44. House of Lords. The Future of Seaside Towns; House of Lords Select Committee on Regenerating Seaside Towns and Communities: London, UK, 2019.

45. Woolf, S.H.; Aron, L. Failing health of the United States. BMJ 2018, 360, k496. [CrossRef]

46. Canetto, S.; Sakinofsky, I. The gender paradox in suicide. Suicide Life-Threat. Behav. 1998, 28, 1-23.

47. Pirkis, J.; Currier, D.; Butterworth, P.; Milner, A.; Kavanagh, A.; Tibble, H.; Robinson, J.; Spittal, M.J.; O'Connor, R.; Portzky, G. Socio-Economic Position and Suicidal Ideation in Men. Int. J. Environ. Public Health 2017, 14, 365. [CrossRef]

48. Mallon, S.; Galway, K.; Hughes, L.; Rondón-Sulbarán, J.; Leavey, G. An exploration of integrated data on the social dynamics of suicide among women. Sociol. Health Illn. 2016, 38, 662-675. [CrossRef] [PubMed]

49. Tsai, A.C.; Lucas, M.; Kawachi, I. Association between social integration and suicide among women in the United States. JAMA Psychiatry 2015, 72, 987-993. [CrossRef] [PubMed]

50. Swami, V.; Stanistreet, D.; Payne, S. Masculinities and suicide. Psychologist 2008, 21, 308-311.

51. HM Government. 2017 Drug Strategy; HM Govt: London, UK, 2017.

52. The Samaritans. Socioeconomic Disadvantage and Suicidal Behaviour; The Samaritans: Ewell, Surrey, UK, 2017.

53. Best, N.; Richardson, S.; Thomson, A. A comparison of Bayesian spatial models for disease mapping. Stat. Methods Med. Res. 2005, 14, 35-59. [CrossRef]

54. Besag, J.; York, J.; Mollié, A. Bayesian image restoration, with two applications in spatial statistics. Ann. Inst. Stat. Math. 1991, 43, 1-20. [CrossRef]

55. Ernstsen, L.; Strand, B.; Nilsen, S.M.; Espnes, G.; Krokstad, S. Trends in absolute and relative educational inequalities in four modifiable ischaemic heart disease risk factors. BMC Public Health 2012, 12, 266. [CrossRef]

(C) 2019 by the author. Licensee MDPI, Basel, Switzerland. This article is an open access article distributed under the terms and conditions of the Creative Commons Attribution (CC BY) license (http://creativecommons.org/licenses/by/4.0/). 